\title{
Magnetic resonance imaging and magnetic resonance venography features in heat stroke: a case report
}

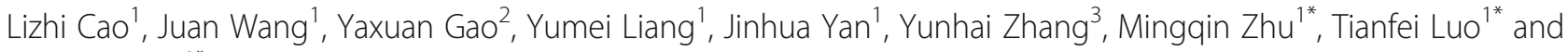
Jiafeng Chen ${ }^{1 *}$

\begin{abstract}
Background: Heat stroke (HS) is a critical illness that can cause multiple organ dysfunction, including damage to the central nervous system (CNS), which can be life-threatening in severe cases. Brain lesions in patients with HS who present with CNS damage have been rarely reported before, and they usually vary in different cases, hence, patients with such lesions may present a clinical challenge in terms of diagnosis and management. Cerebral venous thrombosis (CVT) is a rare cause of stroke that mostly affects young individuals and children. The pathogenesis of brain damage caused by HS is complex, and CVT may be involved in the pathogenesis of HS with CNS damage. In this manuscript, we have reported a case of a patient with HS having CVT with symmetrical lesions in the bilateral putamen, posterior limb of the internal capsule, external capsule, insular lobe, and subcortical white matter in the brain.

Case presentation: We encountered a 48-year-old man who presented with HS in the summer season. During admission, he had a high body temperature and was in coma and shock. Then, he developed rhabdomyolysis syndrome, acute kidney and liver damage, electrolyte imbalance, and acid-base balance disorders, and his Ddimer level was elevated. After several days of anti-shock treatment, the patient's level of consciousness improved. However, he experienced a decline in vision. Cerebral magnetic resonance imaging (MRI) showed symmetrical lesions in the bilateral posterior limb of the internal capsule, putamen, external capsule, insula, and subcortical white matter, and cerebral magnetic resonance venography (MRV) showed the development of CVT. Therefore, anti-coagulation treatment was provided. After timely clinical intervention, the symptoms of the patient gradually improved.
\end{abstract}

Conclusions: This case showed that HS can cause CVT. Therefore, cerebral MRI findings in HS must be assessed; in addition, early MRV can help in the diagnosis of the disease, which can effectively improve prognosis.

Keywords: Heat stroke, Cerebral venous thrombosis, Magnetic resonance imaging, Magnetic resonance venography, Brain lesions

\section{Background}

Heat stroke (HS) is a systemic inflammatory response syndrome with a pathophysiological process similar to that of severe sepsis. The main clinical symptoms of such a condition are core body temperature greater than $40^{\circ} \mathrm{C}$ and multiple organ dysfunction, including damage to the central nervous system (CNS). CNS abnormalities

\footnotetext{
*Correspondence: mingqin.zhu@hotmail.com; tianfeiluo@163.com; jialuochen@163.com

'Department of Neurology, The First Hospital of Jilin University, Changchun 130021, Jilin, China

Full list of author information is available at the end of the article
}

include inattention, memory loss, paralysis, convulsions, and coma. Multiple organ dysfunction syndrome can occur in critically ill patients. The common complications of $\mathrm{HS}$ are acute respiratory distress syndrome, disseminated intravascular coagulation (DIC), shock, rhabdomyolysis, acid-base or electrolyte disorders, renal failure, cerebral edema, and liver dysfunction $[1,2]$. Changes in the cerebral image of patients with HS have been rarely reported, and the mechanism of CNS damage caused by HS is not fully understood. In addition, it

(C) The Author(s). 2019 Open Access This article is distributed under the terms of the Creative Commons Attribution 4.0 International License (http://creativecommons.org/licenses/by/4.0/), which permits unrestricted use, distribution, and 

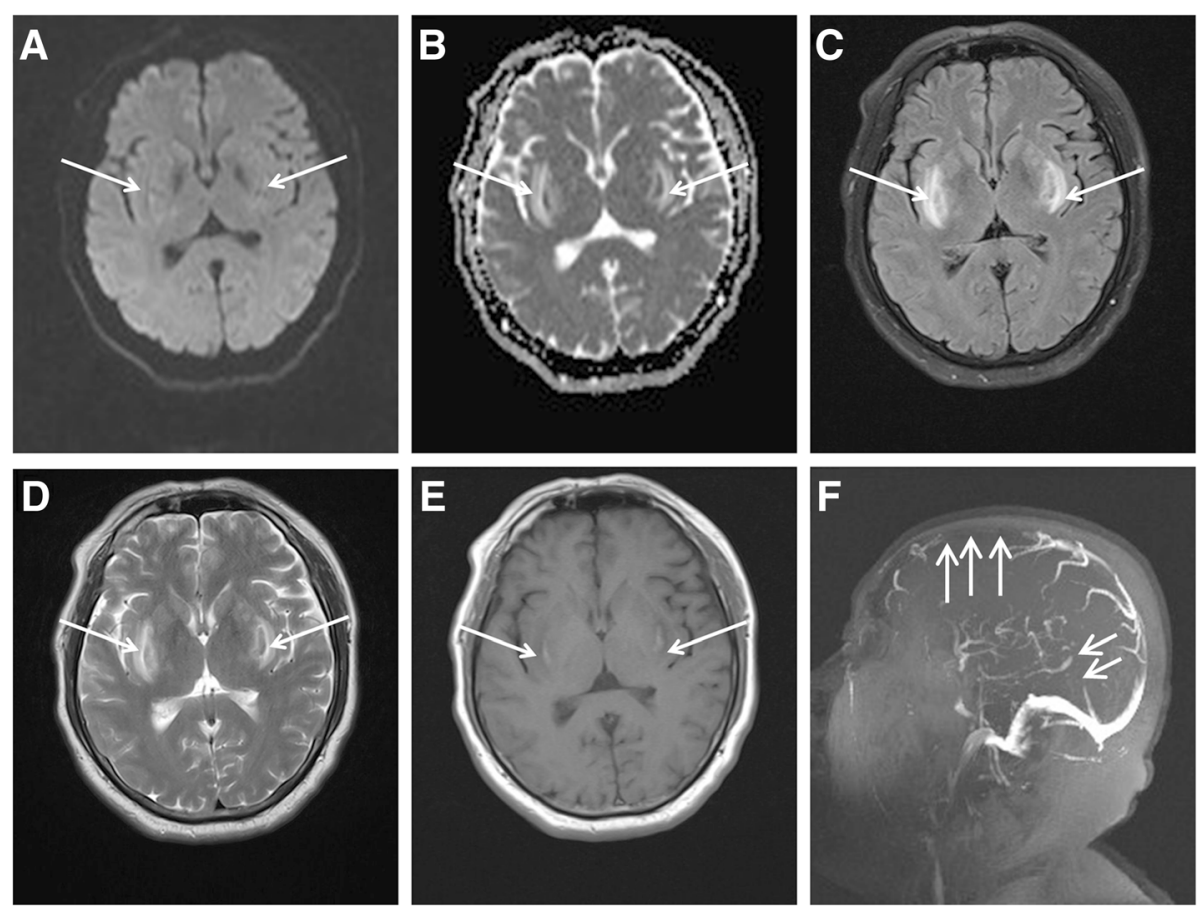

Fig. 1 a-f. Brain magnetic resonance imaging (MRI) was performed 8 days after admission. Cerebral MRI revealed a slight hyperintense signal in the bilateral putamen on a diffusion-weighted imaging sequence and bilateral symmetrical hypointensity in the middle of the putamen as well as hyperintensity around hypointensity on $\mathbf{b}$ apparent diffusion coefficient, $\mathbf{c}$ fluid-attenuated inversion recovery, and $\mathbf{d}$ T2-weighted imaging sequence. The lesions were hyperintense in the middle of the bilateral putamen and hypointense around them on e T1-weighted imaging sequence. $\mathbf{f}$ The inferior sagittal sinus, straight sinus, and vein of Galen were not observed on magnetic resonance venography (MRV) performed on the 12th day of admission. The superior sagittal sinus was poorly developed based on MRV

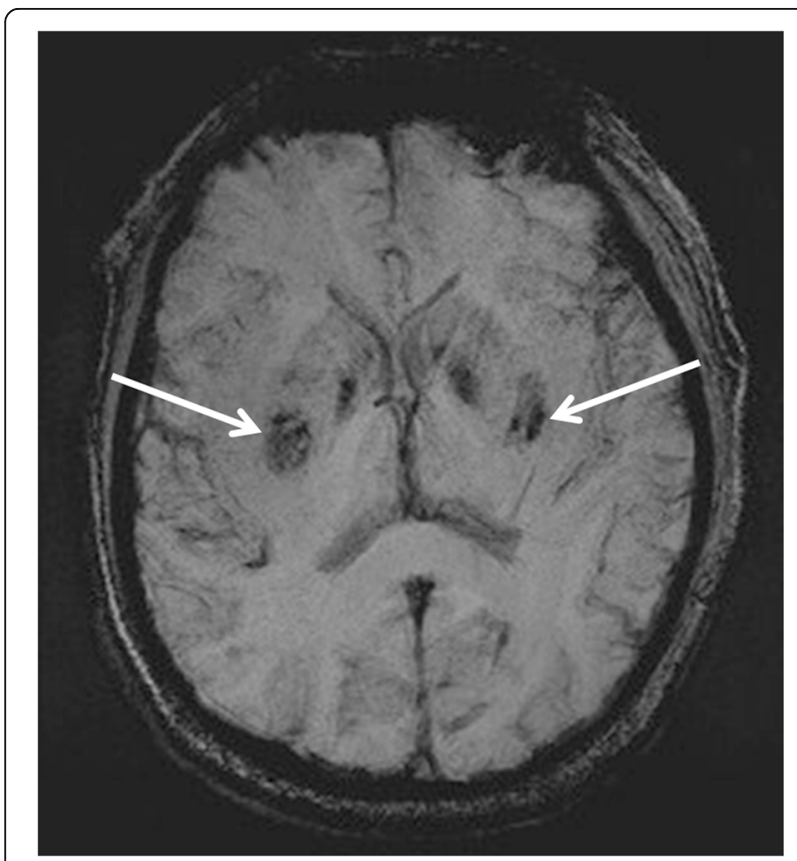

Fig. 2 Susceptibility-weighted imaging conducted on day 17 indicated bilateral hemosiderin deposition or hemorrhagic foci in the basal ganglia remains unclear which parts of the brain are more susceptible to damage caused by HS.

Cerebral venous thrombosis (CVT) is a rare form of cerebrovascular disease. Young individuals and children constitute the main patient groups with CVT. Due to the age of onset and the different causes of CVT, its clinical manifestations are diverse. The common clinical manifestations of CVT include high intracranial pressure symptoms (headache, papilledema, and vomiting), focal symptoms, and encephalopathy-like symptoms. Encephalopathy-like symptoms are rare; however, most symptoms are severe, and the patient can develop epilepsy, mental disorders, and confusion and can go into coma [3]. CVT is associated with several risk factors, which include pregnancy/puerperium, use of oral contraceptive, dehydration, cancer, and infections. The most common brain parenchymal lesions of CVT are intracerebral infarction and hemorrhage [4], followed by focal cerebral edema, such as lesions in the thalamus and basal ganglia, caused by obstruction in the deep venous system [5].

In this article, we report a case of HS with CVT with symmetrical lesions in both sides of the basal ganglia.

\section{Case presentation}

During a hot afternoon in July, a 48-year-old man developed symptoms, such as nausea, vomiting, headache, 

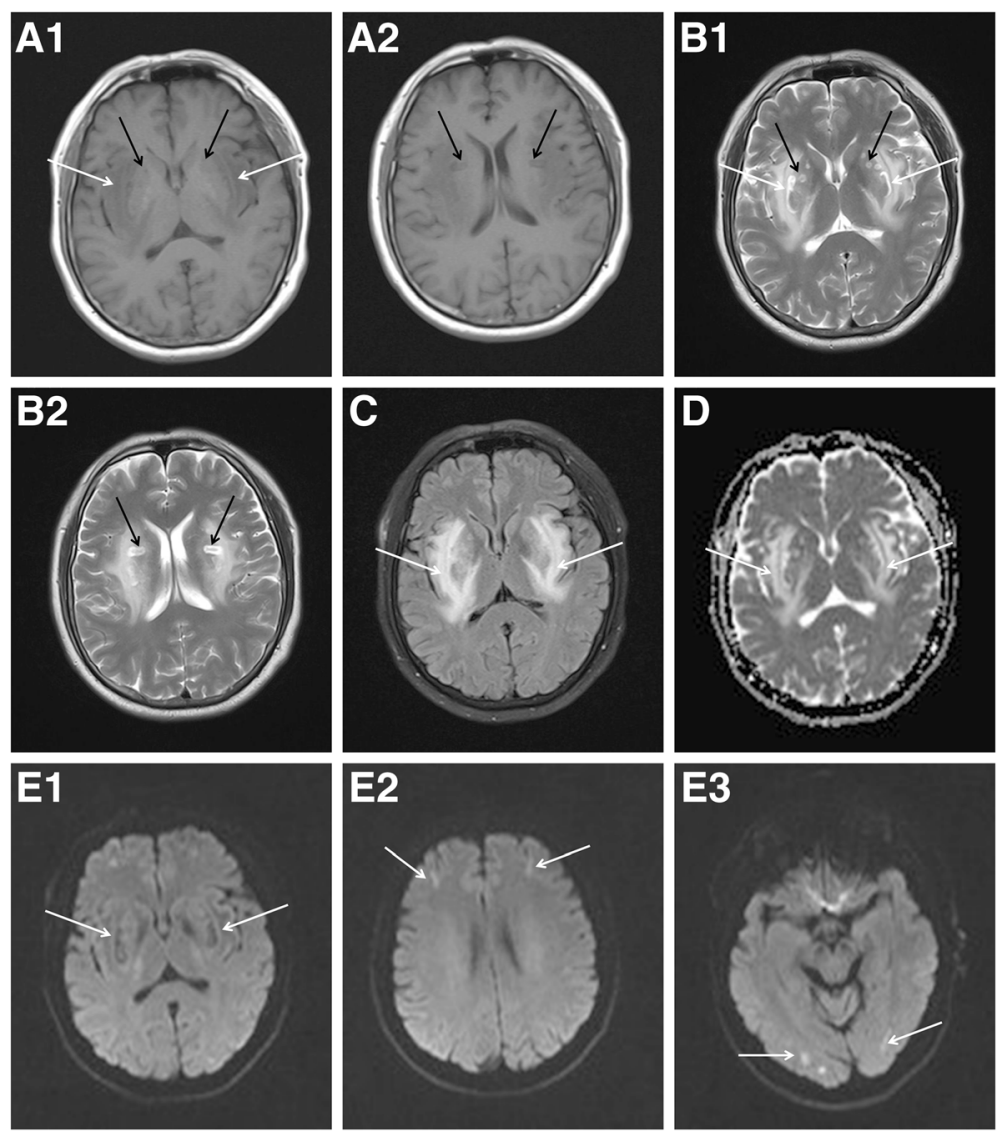

Fig. 3 a1-e3. Follow-up magnetic resonance imaging obtained 25 days after admission showed symmetrical abnormal signals in the bilateral posterior limb of the internal capsule, putamen, extern al capsule, and insular lobe. The signals were hypointense on T1-weighted imaging sequence (T1WI) (a1, white arrows) and hyperintense on T2-weighted imaging sequence (T2WI) (b1, white arrows), (c) fluid-attenuated inversion recovery, and (d) apparent diffusion coefficient. They were not limited by diffusion on (e1) diffusion-weighted imaging (DWI). Strip and dot-like signals, which were isointense and slightly hypointense on T1WI (a1-2, black arrows) and hypointense on T2WI (b1-2, black arrows), can be observed in the lesions. (e2-3) DWI revealed bilateral hyperintensity in the frontal and occipital lobes

chest tightness, and shortness of breath, while working outdoors for $2 \mathrm{~h}$ in a southern city in China. The outside temperature at that time was $35^{\circ} \mathrm{C}$. Notably, the patient lived in the north part of China and had traveled to the southern part when he was sick. After $15 \mathrm{~h}$, he went into coma and was then transferred to the emergency department of the hospital. The patient was in good health before the onset of the disease. Upon arrival, the temperature of the patient was $40.2{ }^{\circ} \mathrm{C}$, blood pressure was $75 / 40 \mathrm{mmHg}$, and pulse rate was 100 beats $/ \mathrm{min}$. His blood oxygen saturation under balloon-assisted ventilation was $95 \%$. Laboratory tests indicated rhabdomyolysis syndrome, acute kidney injury, hepatic disfunction, hyperkalemia, and metabolic acidosis. The serum Ddimer level of the patient was elevated at 1022 (normal range: $0-232) \mu \mathrm{g} / \mathrm{L}$. Therefore, the patient was diagnosed with HS. He was immediately treated with a cooling blanket and plasma exchange and received assisted ventilation. Brain CT scans performed on the 3rd day of admission showed symmetrical low-density lesions in the bilateral basal ganglia. On the 7th day of admission, the patient's state of consciousness improved. However, he experienced blurred vision. Eye examination results were normal. Brain magnetic resonance imaging (MRI) was performed 8 days after admission. Cerebral MRI revealed a slight hyperintensity in the bilateral putamen on diffusion-weighted imaging (DWI) sequence and bilateral symmetrical hypointensity in the middle of the putamen and hyperintensity around hypointensity on the apparent diffusion coefficient (ADC), fluid-attenuated inversion recovery (FLAIR), and T2-weighted imaging (T2WI) sequence. The lesions showed hyperintensity in the middle of the bilateral putamen and hypointensity around them on T1-weighted imaging (T1WI) sequence (Fig. 1A-E). Magnetic resonance venography (MRV) in sagittal projection performed on the 12th day of admission showed the absence of a straight sinus and vein of Galen, indicating CVT. In addition, the lack of flow signal was 
also found in the distal part of the superior sagittal sinus that also corresponds to CVT (Fig. 1F). Intravenous treatment of mannitol, subcutaneous injection of lowmolecular-weight heparin calcium (5000 IU, two times/ day) was initiated to reduce high intracranial pressure and to treat CVT. Cerebrospinal fluid (CSF) examination conducted on day 17 showed elevated protein levels at 1.87 (normal range: $0.15-0.45 \mathrm{~g} / \mathrm{L}$ and immunoglobulin G levels at 267.0 (normal range: $0-34.0$ ) $\mathrm{mg} / \mathrm{L}$. The CSF pressure was 210 (normal range: $80-180$ ) $\mathrm{mmH}_{2} \mathrm{O}$. Susceptibility-weighted imaging (SWI) obtained on the same day indicated bilateral hemosiderin deposition or hemorrhagic foci in the basal ganglia (Fig. 2). Follow-up MRI obtained 25 days after admission showed symmetrical abnormal signals in the bilateral posterior limb of the internal capsule, putamen, external capsule, and insular lobe. The signals were hypointense on T1WI and hyperintense on T2WI, FLAIR, and ADC and were not limited by diffusion on DWI. Strip and dot-like signals, which were isointense and slightly hypointense on T1WI and hypointense on T2WI, can be observed in the lesions. DWI revealed bilateral hyperintensity on the frontal and occipital lobes (Fig. 3A1-E3). The flow signals of the superior sagittal sinus, straight sinus, and vein of Galen were significantly better on follow-up MRV (Fig. 4). On the 28th day of admission, after the administration of gadolinium, MRI revealed abnormal enhancement within the bilateral basal ganglia, and the size of the lesions decreased on MRI conducted 25 days after admission (Fig. 5). The patient was discharged with blurred vision on the 38th day. (Timeline of brain imaging was shown in Table 1).

\section{Discussion and conclusions}

Severe HS can be life-threatening, and nearly 30\% of survivors present with permanent neurological sequelae [1]. The damage in the CNS due to HS is caused by a variety of factors. Heat itself is toxic to the brain cells (such as Purkinje cells of the cerebellum) [6]. Excessive secretion of cytokines, such as interleukin-1, can disrupt the blood-brain barrier, which in turn leads to vasogenic edema [7]. Lesions in a patient with HS that are hyperintense on DWI and hypointense on ADC may indicate cell-derived edema rather than vasogenic edema [8]. DIC can cause intracerebral hemorrhage, and microthrombus derived from DIC can cause small vessel ischemic injury. Incomplete circulatory function can lead to cerebral ischemia and hypoxic injury. Myelin can dissolve due to metabolic disorders [9]. In addition, recent studies have shown that excitotoxic injury may also be involved in the pathogenesis of HS. Li J and his coworkers have found that the $\mathrm{N}$-acetyl aspartate/creatine value was low on magnetic resonance spectroscopy imaging of patients with HS [10].

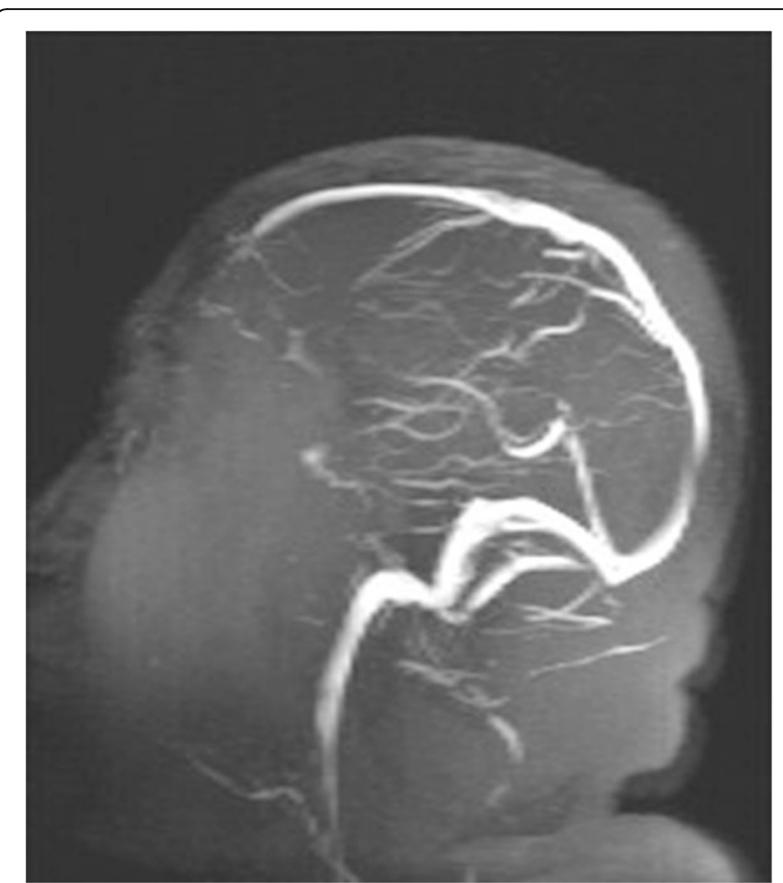

Fig. 4 The flow signals of the superior sagittal sinus, straight sinus, and vein of Galen were significantly better on follow-up magnetic resonance venography performed on the 25th day after admission

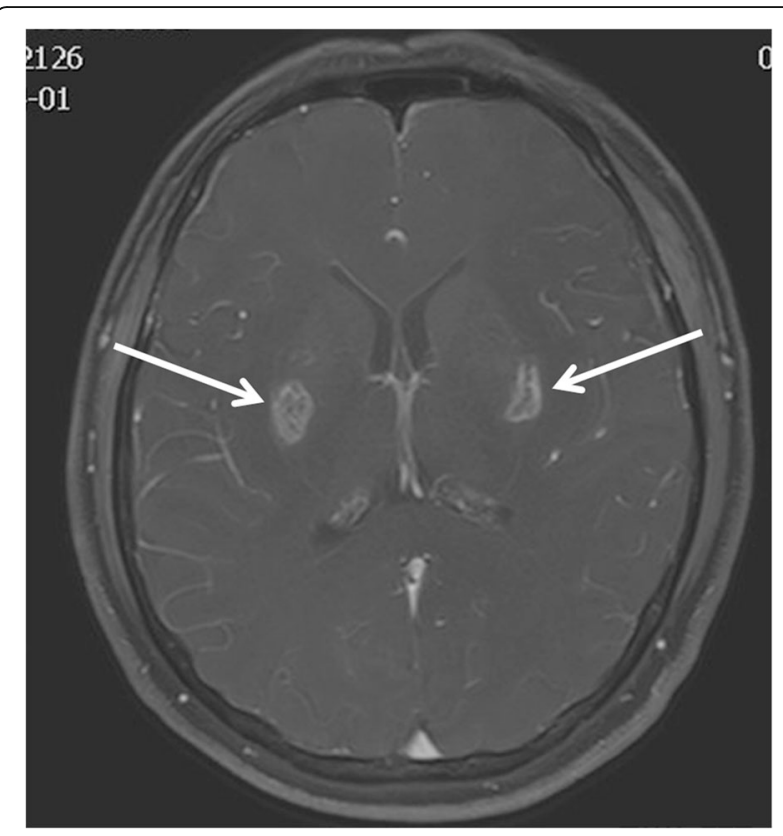

Fig. 5 On day 28, magnetic resonance imaging (MRI) after gadolinium was administered revealed abnormal enhancement within the bilateral basal ganglia, and the size of the lesions decreased on MRI conducted 25 days after admission 
Table 1 Timeline of Brain Imaging

\begin{tabular}{|c|c|c|}
\hline Day & Brain CT scan/MRI Findings & Brain MRV Findings \\
\hline 3 & Symmetrical low-density lesions in the bilateral basal ganglia on CT scan. & ND \\
\hline 8 & $\begin{array}{l}\text { Slight hyperintensity in the bilateral putamen on DWI. Bilateral symmetrical } \\
\text { hypointensity in the middle of the putamen and hyperintensity around } \\
\text { hypointensity on ADC, FLAIR, and T2WI. Hyperintensity in the middle of } \\
\text { the bilateral putamen and hypointensity around them on T1WI. }\end{array}$ & ND \\
\hline 12 & ND & $\begin{array}{l}\text { Inferior sagittal sinus, straight sinus, and vein of Galen } \\
\text { were not observed on MRV. The superior sagittal sinus } \\
\text { was poorly developed on MRV. }\end{array}$ \\
\hline 17 & $\begin{array}{l}\text { Bilateral hemosiderin deposition or hemorrhagic foci in the basal ganglia } \\
\text { on SWI. }\end{array}$ & ND \\
\hline 25 & $\begin{array}{l}\text { Symmetrical abnormal signals in the bilateral posterior limb of the internal } \\
\text { capsule, putamen, external capsule, and insular lobe. The signals were } \\
\text { hypointense on T1WI and hyperintense on T2WI, FLAIR, and ADC and were } \\
\text { not limited by diffusion on DWI. Strip and dot-like signals, which were } \\
\text { isointense and slightly hypointense on T1WI and hypointense on T2WI, can } \\
\text { be observed in the lesions. Bilateral hyperintensity on the frontal and } \\
\text { occipital lobes on DWI. }\end{array}$ & $\begin{array}{l}\text { The flow signals of the superior sagittal sinus, straight } \\
\text { sinus, and vein of Galen were significantly better on } \\
\text { follow-up MRV. }\end{array}$ \\
\hline 28 & $\begin{array}{l}\text { Abnormal enhancement within the bilateral basal ganglia on MRI after the } \\
\text { administration of gadolinium. }\end{array}$ & ND \\
\hline
\end{tabular}

"ND" represents "Not Done"

For several years, only few cases with imaging findings of the CNS have been reported. Brain lesions caused by HS are usually symmetrical on imaging examination. Based on MRI findings in the literature, the lesions are mainly distributed in the cerebellum, thalamus, basal ganglia, cerebral cortex, brainstem, hippocampus, subcortical white matter, external capsule, and splenium. The lesions of the cerebellum are mainly concentrated in the cerebellar cortex, superior cerebellar peduncle, vermis of the cerebellum, and corpora dentatum. In addition, the common lesion site is the caudate nucleus of the basal ganglia [6, 7, 9, 11-18]. However, our case involved symmetrical lesions in both sides of the posterior limb of the internal capsule, putamen, external capsule, insular lobe, and subcortical white matter, which has not been reported before. Due to the selective vulnerability of cerebellar neurons and Purkinje cells to thermal damage $[14,19]$, the cerebellum is likely to be damaged in HS. Several patients with HS present with cerebellar symptoms, such as ataxia [20]. Although some studies have found cerebellar atrophy delays on radiographic images [21], no abnormal signals were found in the cerebellum in our patient on MRI.

The literature shows that brain damage caused by HS appears as hyperintense lesions on the following imaging sequences: T2WI and FLAIR [9, 11], DWI and FLAIR [12], and T1WI and T2WI. Sometimes these anomalous signals are limited to DWI [13]. However, the lesions in our case showed high and low mixed signals in the abovementioned sequences. Lesions can be enhanced occasionally on contrast-enhanced imaging. Cerebral lesions in patients with HS showed punctiform hemorrhage on SWI [22].
Shock is one of the numerous risk factors of CVT [23]. Dentali F et al. have reported that D-dimer in CVT has a sensitivity of 94\% [24]. The deep venous system consists of the straight sinus, vein of Galen, and internal cerebral veins. MRI of deep cerebral venous thrombosis (DCVT) can often observe bilateral thalamic lesions involving the basal ganglia [25]. During admission, the patient was in shock and his D-dimer level was elevated. Due to the presence of bilateral basal ganglia lesions, we prescribed MRV examination and found some abnormalities. In the literature, data about MRV changes in patients with HS are limited; thus, the findings in this case must be reported. Interestingly, the patient's lesions were mainly located in the bilateral basal ganglia, not in the thalamus, which is different from the common lesions of DCVT. Two previous studies have shown that low-molecular-weight heparin is more suitable for the treatment of uncomplicated CVT than unfractionated heparin [26, 27]. In general, patients with CVT can achieve a good prognosis after treatment [28]. In a study by Arauz A et al., approximately $90 \%$ of patients with obstructed cerebral veins were recanalized [29]. In our study, after the patient was treated with low-molecularweight heparin for 13 days, the second MRV was performed on the 25th day of admission, and results showed recanalization of the obstructed cerebral veins. On day 38, the patient was discharged with blurred vision, and the Modified Rankin Scale score was 2 .

The mechanism of brain damage caused by HS is complex and diverse, and its cerebral imaging changes vary. Herein, we have reported a patient with high and low mixed signals in the bilateral posterior limb of the internal capsule, putamen, external capsule, insula, and 
subcortical white matter on MRI, and his MRV showed development of CVT. After treatment, the obstructed cerebral veins were recanalized. We believe that when the cerebral MRI findings of patients with HS need to be identified, MRV and other related tests should be performed. Moreover, timely treatment can improve prognosis.

\section{Abbreviations}

ADC: Apparent diffusion coefficient; CNS: Central nervous system; CSF: cerebrospinal fluid; CVT: Cerebral venous thrombosis; DCVT: Deep cerebral venous thrombosis; DIC: Disseminated intravascular coagulation; DWI: Diffusion-weighted imaging; FLAIR: Fluid-attenuated inversion recovery; HS: Heat strok; MRI: Magnetic resonance imaging; MRV: Magnetic resonance venography; SWI: Susceptibility-weighted imaging; T1WI: T1-weighted imaging; T2WI: T2-weighted imaging

\section{Acknowledgements}

Not applicable.

\section{Authors' contributions}

LZC drafted the manuscript; JW, YXG, YML, JHY and YHZ collected patient information; MQZ, TFL, and JFC interpreted the data and edited the manuscript. All authors read and approved the final manuscript.

\section{Funding}

The study received a grant from Jiangsu Key Laboratory of Medical Optics, Suzhou Institute of Biomedical Engineering and Technology, Chinese Academy of Sciences, Suzhou 215163, China. The authors are also grateful for the support from grants from the National Science Foundation of China (No. 31600820, NO. 81701158); The Health and Family Planning Commission of Jilin Province (No. 2016Q036); The Science and technology planning project of Jilin Province (No. 2018052 0110JH). The Funding supported design of the study and collection, analysis, and interpretation of data and in writing the manuscript.

\section{Availability of data and materials}

All data generated or analysed during this study are included in this published article.

\section{Ethics approval and consent to participate}

This study was approved by the ethics committee of The First Hospital of Jilin University, China.

\section{Consent for publication}

Written informed consent was obtained from the patient prior to the publication of this case report and any accompanying images.

\section{Competing interests}

The authors declare that they have no competing interests.

\section{Author details}

'Department of Neurology, The First Hospital of Jilin University, Changchun 130021, Jilin, China. ${ }^{2}$ Norman Bethune Health Science Center of Jilin University, Changchun 130000, Jilin, China. ${ }^{3}$ Jiangsu Key Laboratory of Medical Optics, Suzhou Institute of Biomedical Engineering and Technology, Chinese Academy of Sciences, Suzhou 215163, China.

\section{Received: 24 February 2019 Accepted: 11 June 2019}

Published online: 18 June 2019

\section{References}

1. Yang M, Li Z, Zhao Y, Zhou F, Zhang Y, Gao J, et al. Outcome and risk factors associated with extent of central nervous system injury due to exertional heat stroke. Medicine (Baltimore). 2017;96(44):e8417.

2. Raukar N, Lemieux RS, Casa DJ, Katch RK. Dead heat: treating exertional heat stroke is a race against time and temperature. Jems. 2017;42(5):54-9.

3. Ferro JM, Canhao P, Aguiar de Sousa D. Cerebral venous thrombosis. Presse Med. 2016:45(12 Pt 2):e429-e50.
4. Coutinho JM, van den Berg R, Zuurbier SM, VanBavel E, Troost D, Majoie CB, et al. Small juxtacortical hemorrhages in cerebral venous thrombosis. Ann Neurol. 2014;75(6):908-16.

5. Coutinho JM. Cerebral venous thrombosis. J Thromb Haemost. 2015: 13(Suppl 1):S238-44.

6. Li J, X-y Z, Z-m Z, Wang B, J-k X. Heat stroke: typical MRI and 1H-MRS features. Clin Imaging. 2015;39(3):504-5.

7. Mahajan S, Schucany WG. Symmetric bilateral caudate, hippocampal, cerebellar, and subcortical white matter MRI abnormalities in an adult patient with heat stroke. Proc (Bayl Univ Med Cent). 2008;21(4):433-6.

8. Fujioka Y, Yasui K, Hasegawa Y, Takahashi A, Sobue G. An acute severe heat stroke patient showing abnormal diffuse high intensity of the cerebellar cortex in diffusion weighted image: a case report. Rinsho Shinkeigaku. 2009; 49(10):634-40

9. Fatih Yilmaz T, Aralasmak A, Toprak H, Guler S, Tuzun U, Alkan A. MRI and MR spectroscopy features of heat stroke: a case report. Iran J Radiol. 2018; 15(3).

10. Li J, Zhang XY, Wang B, Zou ZM, Li HF, Wang PY, et al. Multivoxel proton magnetic resonance spectroscopy in heat stroke. Clin Radiol. 2015;70(1):37-41.

11. Sudhakar PJ, Al-Hashimi H. Bilateral hippocampal hyperintensities: a new finding in MR imaging of heat stroke. Pediatr Radiol. 2007;37(12):1289-91.

12. Fuse A, Yamashiro K, Oji Y, Furuya T, Noda K, Hattori N, et al. Reversible focal cerebral cortical lesions in a patient with heat stroke. Intern Med. 2013; 52(3):377-80.

13. Ookura R, Shiro Y, Takai T, Okamoto M, Ogata M. Diffusion-weighted magnetic resonance imaging of a severe heat stroke patient complicated with severe cerebellar Ataxia. Intern Med. 2009;48(12):1105-8.

14. Lee JS, Choi JC, Kang SY, Kang JH, Park JK. Heat stroke: increased signal intensity in the bilateral cerebellar dentate nuclei and splenium on diffusion-weighted MR imaging. AJNR Am J Neuroradiol. 2009;30(4):E58.

15. Kobayashi K, Tha KK, Terae S, lijima Y, Katabami K, Minami Y, et al. Improved detection of heat stroke-induced brain injury by high b-value diffusionweighted imaging. J Comput Assist Tomogr. 2011;35(4):498-500.

16. De Cori S, Biancofiore G, Bindi L, Cosottini M, Pesaresi I, Murri L, et al. Clinical recovery despite cortical cerebral and cerebellar damage in heat stroke. Neuroradiol J. 2010;23(1):35-7.

17. Lo YC, Yen DH, Guo WY, Yang CC. Diffuse cerebral cortex, cerebellar cortex and basal ganglia injury: a rare MR imaging manifestation of heat stroke. Neuroradiol J. 2007;20(1):37-40.

18. McLaughlin $C T$, Kane AG, Auber AE. MR imaging of heat stroke: external capsule and thalamic T1 shortening and cerebellar injury. AJNR Am J Neuroradiol. 2003;24(7):1372-5.

19. Bazille C, Megarbane B, Bensimhon D, Lavergne-Slove A, Baglin AC, Loirat $P$, et al. Brain damage after heat stroke. J Neuropathol Exp Neurol. 2005;64(11): 970-5.

20. Jakkani RK, Agarwal VK, Anasuri S, Vankayalapati S, Koduri R, Satyanarayan S. Magnetic resonance imaging findings in heat stroke-related encephalopathy. Neurol India. 2017:65(5):1146-8

21. Albukrek D, Bakon M, Moran DS, Faibel M, Epstein Y. Heat-stroke-induced cerebellar atrophy: clinical course, CT and MRI findings. Neuroradiology. 1997;39(3):195-7.

22. Hendrikse J, X-y Z, Li J. Susceptibility-weighted imaging in heat stroke. PLoS One. 2014;9(8).

23. van Gijn J. Cerebral venous thrombosis: pathogenesis, presentation and prognosis. J R Soc Med. 2000;93(5):230-3.

24. Dentali F, Squizzato A, Marchesi C, Bonzini M, Ferro JM, Ageno W. D-dimer testing in the diagnosis of cerebral vein thrombosis: a systematic review and a meta-analysis of the literature. J Thromb Haemost. 2012;10(4):582-9.

25. Lim CC. Magnetic resonance imaging findings in bilateral basal ganglia lesions. Ann Acad Med Singap. 2009;38(9):795-8.

26. Coutinho JM, Ferro JM, Canhao P, Barinagarrementeria F, Bousser MG, Stam J. Unfractionated or low-molecular weight heparin for the treatment of cerebral venous thrombosis. Stroke. 2010:41(11):2575-80.

27. Einhaupl K, Stam J, Bousser MG, De Bruijn SF, Ferro JM, Martinelli I, et al EFNS guideline on the treatment of cerebral venous and sinus thrombosis in adult patients. Eur J Neurol. 2010;17(10):1229-35.

28. Ferro JM, Canhao P, Stam J, Bousser MG, Barinagarrementeria F. Prognosis of cerebral vein and dural sinus thrombosis: results of the international study on cerebral vein and Dural sinus thrombosis (ISCVT). Stroke. 2004; 35(3):664-70. 
29. Arauz A, Vargas-Gonzalez JC, Arguelles-Morales N, Barboza MA, Calleja J,

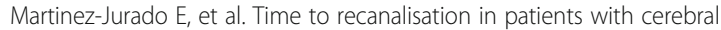
venous thrombosis under anticoagulation therapy. J Neurol Neurosurg Psychiatry. 2016;87(3):247-51.

\section{Publisher's Note}

Springer Nature remains neutral with regard to jurisdictional claims in published maps and institutional affiliations.

Ready to submit your research? Choose BMC and benefit from:

- fast, convenient online submission

- thorough peer review by experienced researchers in your field

- rapid publication on acceptance

- support for research data, including large and complex data types

- gold Open Access which fosters wider collaboration and increased citations

- maximum visibility for your research: over $100 \mathrm{M}$ website views per year

At $B M C$, research is always in progress.

Learn more biomedcentral.com/submissions 